\title{
Effect of resting heart rate on two-year clinical outcomes of high-risk patients with severe symptomatic aortic stenosis undergoing transcatheter aortic valve implantation
}

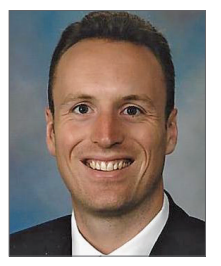

Crochan J. O’Sullivan ${ }^{1,2}$, MD, PhD; Ernest Spitzer ${ }^{1,3}, \mathrm{MD}$; Dik Heg ${ }^{4,5}, \mathrm{PhD}$; Fabien Praz ${ }^{1}, \mathrm{MD}$; Stefan Stortecky ${ }^{1}, \mathrm{MD}$; Christoph Huber ${ }^{5}, \mathrm{MD}$; Thierry Carrel$^{5}$, MD; Thomas Pilgrim¹, MD; Stephan Windecker ${ }^{6 *}$, MD

1. Department of Cardiology, Bern University Hospital, Bern, Switzerland; 2. Department of Cardiology, Stadtspital Triemli, Zürich, Switzerland; 3. Cardialysis, Clinical Research Management \& Core Laboratories, Rotterdam, The Netherlands; 4. Clinical Trials Unit, Bern University Hospital, Bern, Switzerland; 5. Institute of Social and Preventive Medicine, University of Bern, Bern, Switzerland; 6. Department of Cardiovascular Surgery, Bern University Hospital, Bern, Switzerland

C. O'Sullivan and E. Spitzer contributed equally to this article.

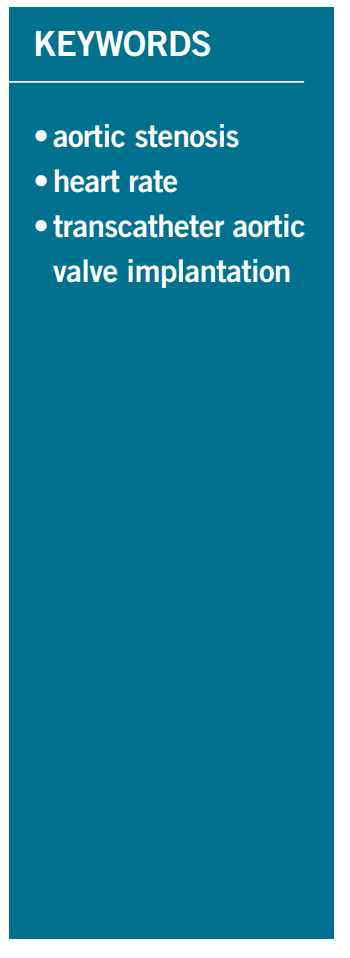

\begin{abstract}
Aims: Resting heart rate $\left(\mathrm{HR}_{\mathrm{ate}}\right)$ is a modifiable risk factor among patients with cardiovascular disease, including aortic stenosis (AS). However, the effect of resting $\mathrm{HR}_{\mathrm{ate}}$ on clinical outcomes of patients with severe symptomatic AS undergoing transcatheter aortic valve implantation (TAVI) is unknown. Our aim was therefore to assess the effect of resting $\mathrm{HR}_{\text {ate }}$ on clinical outcomes among high-risk patients with symptomatic severe AS in normal sinus rhythm (NSR) undergoing TAVI.
\end{abstract}

Methods and results: Of 606 consecutive patients undergoing TAVI, 349 (57.6\%) with severe AS and a baseline 12-lead electrocardiogram (ECG) showing NSR undergoing TAVI were analysed. Patients were dichotomised into low $\mathrm{HR}_{\text {ate }}$ (LHR; $<77$ beats per minute $\left.[\mathrm{bpm}]\right)$ and high $\mathrm{HR}_{\text {ate }}(\mathrm{HHR} ; \geq 77 \mathrm{bpm}$ ) groups. The primary endpoint was all-cause mortality at two years. As compared with baseline LHR, no significant differences in all-cause mortality at two years (adjusted [adj] hazard ratio [HR] 1.23, $\mathrm{p}=0.40$ ) were observed among patients with baseline HHR. Of 197 patients with available discharge ECGs remaining in $\mathrm{NSR}$, mean $\mathrm{HR}_{\text {ate }}$ significantly increased among LHR patients $\left(\Delta \mathrm{HR}_{\text {ate }} 8.35, \mathrm{p}<0.001\right)$ but decreased among HHR patients $\left(\Delta \mathrm{HR}_{\mathrm{ate}}-4.88, \mathrm{p}<0.001\right)$. On thirty-day landmark analysis, discharge HHR was significantly associated with two-year all-cause mortality (HR 2.30, 95\% CI: 1.16-4.56, $\mathrm{p}=0.017$ ), but not after extensive adjustment for comorbidities (adj HR 2.01, 95\% CI: 0.98-4.09, $\mathrm{p}=0.056$ ). A significant interaction for two-year mortality (p-interaction 0.021) was observed on landmark analysis for discharge, but not baseline, HHR.

Conclusions: Baseline and discharge resting $\mathrm{HR}_{\text {ate }}$ were not associated with adverse outcomes after TAVI.

\footnotetext{
*Corresponding author: Department of Cardiology, Swiss Cardiovascular Center Bern, Bern University Hospital, 3010 Bern,
} Switzerland.E-mail: stephan.windecker@insel.ch 


\section{Introduction}

A high resting heart rate $\left(\mathrm{HR}_{\mathrm{ate}}\right)$ is a potentially modifiable cardiovascular risk factor, both in the general population and among patients with cardiovascular disease ${ }^{1-3}$. Large observational studies have shown a link between increased $\mathrm{HR}_{\text {ate }}$ and all-cause mortality and cardiovascular events in patients with coronary artery disease, hypertension, metabolic syndrome and heart failure ${ }^{4-7}$. A high resting $\mathrm{HR}_{\text {ate }}$ has recently been shown to be associated with major cardiovascular events and cardiovascular death among patients with asymptomatic aortic stenosis (AS) ${ }^{8}$. In addition, it was recently demonstrated that sympathetic nervous system (SNS) activity is increased and arterial baroreflex is impaired in patients with AS undergoing transcatheter aortic valve implantation (TAVI) 9 . A high $\mathrm{HR}_{\text {ate }}$ reflects an increase in SNS activity, which may trigger or exacerbate many of the pathophysiological features associated with AS, such as cardiac hypertrophy and decreased peripheral perfusion'. While there have been several studies published to date assessing the effect of rhythm disturbances (e.g., atrial fibrillation $^{10,11}$ ) and conduction abnormalities (e.g., left bundle branch block $^{12,13}$ ) on clinical outcomes after TAVI, the majority of patients remain in normal sinus rhythm after TAVI ${ }^{10,11}$. Heart rate is an easily modifiable risk factor and therefore it is clinically useful to determine whether or not an elevated heart rate may affect clinical outcomes after TAVI. However, to the best of our knowledge, this association has never before been investigated. We therefore aimed to assess the effect of resting $\mathrm{HR}_{\text {ate }}$ on clinical outcomes among high-risk patients with symptomatic severe AS in normal sinus rhythm undergoing TAVI.

\section{Editorial, see page 417}

\section{Methods \\ PATIENT POPULATION}

This is a retrospective analysis of prospectively collected data from a database that includes all patients with severe native valve AS who underwent TAVI at our institution between August 2007 and December $2012(\mathrm{n}=606)$. All patients were deemed inoperable or at high surgical risk for conventional surgery by a multidisciplinary team comprising interventional cardiologists and cardiovascular surgeons. Patient flow is shown in Figure 1. Included in this study were all consecutive patients with symptomatic severe native valve AS in sinus rhythm on 12-lead electrocardiogram (ECG) performed $\leq 30$ days prior to TAVI. Exclusion criteria are shown in Figure 1. Patients were dichotomised into low ( $<77$ beats per minute $[\mathrm{bpm}])$ and high $(\geq 77 \mathrm{bpm}) \mathrm{HR}_{\text {ate }}$ groups according to the baseline $\mathrm{HR}_{\text {ate }}$ measured on the pre-procedural 12-lead ECG. Discharge 12-lead ECGs were subsequently analysed after TAVI to assess the discharge $\mathrm{HR}_{\text {ate }}$ and any changes in $\mathrm{HR}_{\text {ate }}$ occurring after TAVI. A cut-off $\mathrm{HR}_{\text {ate }}$ of $77 \mathrm{bpm}$ was chosen based on the results of the randomised Systolic Heart failure treatment with the $\mathrm{I}_{f}$ inhibitor ivabradine Trial (SHIFT), where evidence of a significant treatment effect with ivabradine was noted only in the subgroup of patients with baseline heart rates higher than the median $77 \mathrm{bpm}^{14}$.

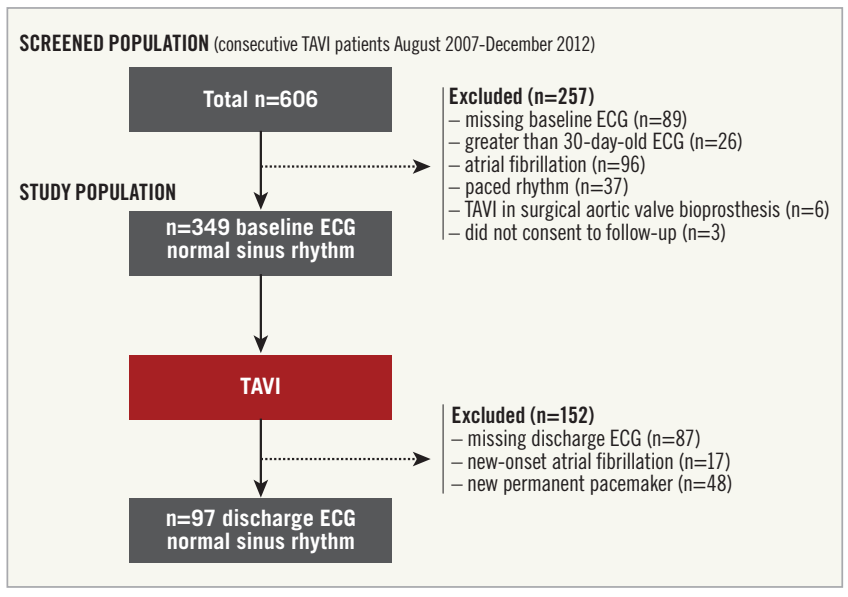

Figure 1. Patient flow for the study population.

The cohort study complies with the Declaration of Helsinki, was approved by the local ethics committee, and all patients provided written informed consent.

\section{ELECTROCARDIOGRAPHY AND ECHOCARDIOGRAPHY}

Available 12-lead ECGs were analysed individually by two cardiologists unaware of clinical data. Discrepancies were resolved through consensus. Transthoracic echocardiography was performed in all included patients at baseline as previously described ${ }^{15}$.

\section{CARDIAC CATHETERISATION}

All TAVI patients underwent coronary angiography and 290/349 $(83 \%)$ had a full invasive evaluation by right and left heart catheterisation prior to TAVI as previously described ${ }^{16}$.

\section{TRANSCATHETER AORTIC VALVE IMPLANTATION PROCEDURE}

TAVI was performed as previously described. Vascular access was transfemoral using the Medtronic CoreValve Revalving System (MCRS) (Medtronic, Minneapolis, MN, USA), Edwards SAPIEN/XT (ESV) (Edwards Lifesciences, Irvine, CA, USA) or transapical for the latter bioprosthesis or the self-expanding Symetis ACURATE $\mathrm{TA}^{\mathrm{TM}}$ valve (SA) (Symetis Inc., Ecublens, Switzerland) or trans-subclavian using the MCRS ${ }^{16}$.

\section{CLINICAL FOLLOW-UP}

Adverse events were assessed in hospital, and regular clinical follow-up was performed at one, six, 12 and 24 months by means of a clinical visit or standardised telephone interview. All suspected events were adjudicated by an unblinded clinical events committee, comprising cardiac surgeons and interventional cardiologists who were unaware of the heart rate assessments.

\section{STUDY ENDPOINTS}

Clinical endpoints were defined according to the criteria proposed by the Valve Academic Research Consortium-2 (VARC-2) consensus document ${ }^{17}$. The primary endpoint was all-cause mortality at two 
years. The secondary endpoint was cardiovascular death at two years. All endpoints were assessed for both baseline and discharge $\mathrm{HR}_{\text {ate }}$.

\section{STATISTICS}

Continuous data are presented as means \pm standard deviations (SD), and categorical variables are shown as percentages and numbers. Categorical variables were compared by means of the $\chi^{2}$ test (or Fisher's test for two-group comparisons), and continuous variables were compared using the unpaired t-test. Time-to-event data are presented using Kaplan-Meier curves, with incidence rates calculated from life tables at two-year follow-up. Univariate and adjusted Cox proportional hazards models were used to derive hazard ratio estimates of clinical time-to-event comparisons between the two groups. Inverse probability of treatment weighted (IPTW) hazard ratios (HR) and 95\% confidence intervals (CI) were derived from Cox regressions. IPTW values for high versus low heart rate at baseline, and again separately for heart rate at discharge, were calculated using the following baseline clinical variables: age, gender, height, body mass index, diabetes, coronary artery disease (CAD), multivessel CAD disease, previous myocardial infarction, cardiac surgery, percutaneous coronary intervention, peripheral vascular disease, chronic obstructive pulmonary disease (COPD), renal failure, moderate or severe mitral regurgitation, New York Heart Association (NYHA) functional Class III or IV (selected if $\mathrm{p}<0.2$ on all-cause death at two years or $\mathrm{p}<0.2$ on high vs. low). Missing data were replaced with single imputation (COPD, NYHA III or IV, mitral regurgitation, $\mathrm{n}=1,1$, and 32, respectively). The changes in heart rate from baseline pre-TAVI to discharge post-TAVI were analysed with paired t-tests and linear regression. All p-values and 95\% CI are two-sided. Two-sided p-values $<0.05$ were considered statistically significant. All analyses were performed with Stata version 14 (StataCorp, College Station, TX, USA).

\section{Results \\ BASELINE CHARACTERISTICS}

Patient characteristics are shown in Table 1. The present analysis included 349 patients out of 606 consecutive patients (58\%) undergoing TAVI between August 2007 and December 2012 in our institution. Of the 349 included patients in sinus rhythm prior to TAVI, $219(63 \%)$ had a low resting $\mathrm{HR}_{\text {ate }}$ (LHR) (defined as $<77 \mathrm{bpm}$ ) and $130(37 \%)$ had a high resting $\mathrm{HR}_{\text {ate }}$ (HHR) (defined as $\geq 77$ bpm) at baseline before TAVI. As compared with LHR, patients with HHR were significantly younger, more likely to be female, less likely to have undergone previous cardiac surgery and previous percutaneous coronary intervention, and were less likely to be taking beta-blockers. ECGs were performed at a mean \pm standard deviation of $3.6 \pm 5.0$ days (range $0-28$ days) prior to TAVI. Data on periprocedural changes in medications, including beta-blockers and calcium channel blockers, are shown in Table 1. We found no significant difference in the prevalence of beta-blockers (56\% vs. $57 \%, \mathrm{p}=0.90)$ or calcium channel blockers $(27 \%$ vs. $21 \%, \mathrm{p}=0.31)$ prescribed at discharge between low and high heart rate patients.

\section{ELECTROCARDIOGRAPHIC, ECHOCARDIOGRAPHIC AND INVASIVE HAEMODYNAMIC CHARACTERISTICS}

Baseline electrocardiographic, echocardiographic and invasive haemodynamic characteristics are shown in Table 2. As compared with LHR, patients with HHR had smaller aortic valve areas, worse LV systolic and diastolic function and a higher prevalence of moderate to severe mitral regurgitation on baseline echocardiography. Patients with HHR also had a more adverse baseline haemodynamic profile on pre-procedural right and left heart catheterisation. Interestingly, despite significantly lower stroke volume indices among HHR patients, no significant differences in cardiac indices were observed between groups. No significant differences in pulmonary artery systolic pressures were observed between

Table 1. Baseline characteristics.

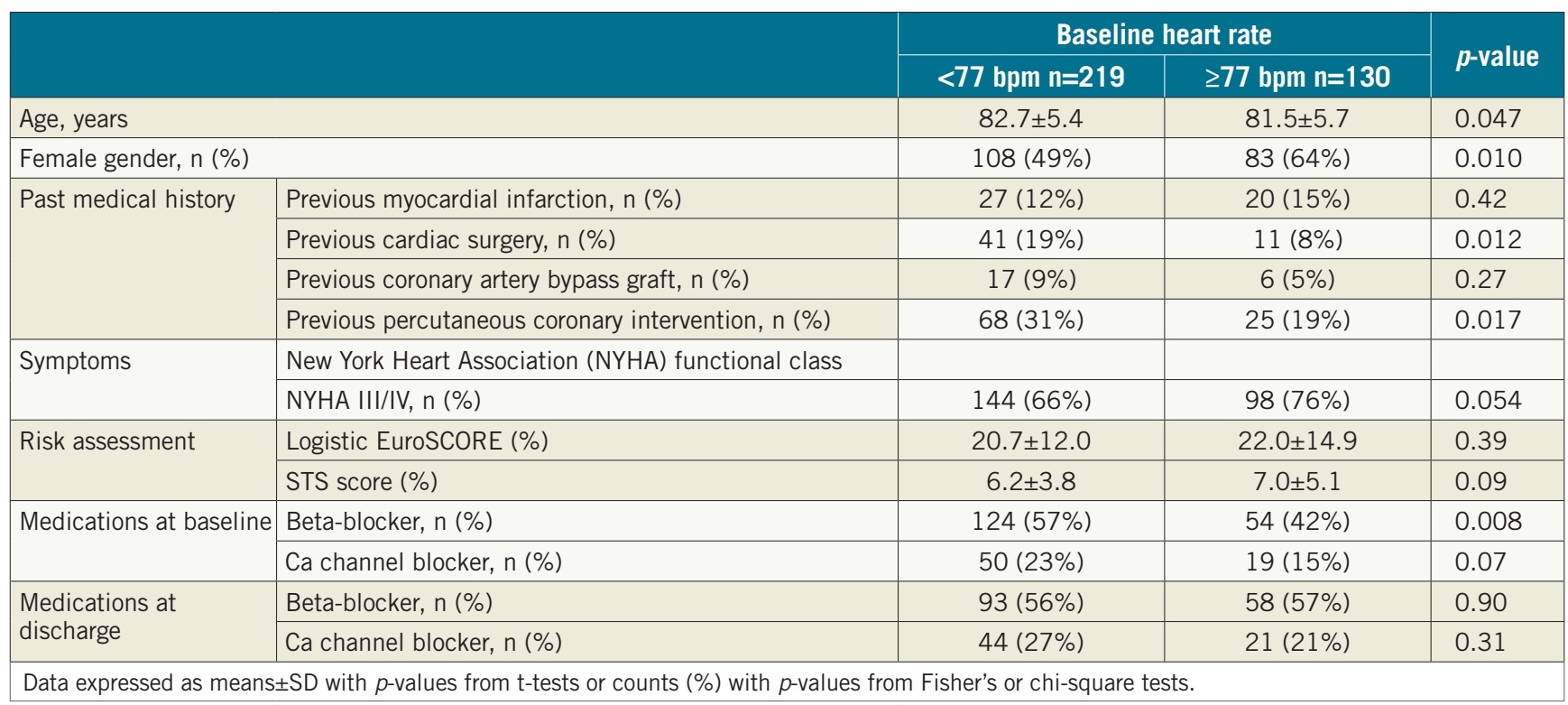


Table 2. Electrocardiographic, echocardiographic and invasive characteristics.

\begin{tabular}{|c|c|c|c|c|}
\hline & & \multicolumn{2}{|c|}{ Baseline heart rate } & \multirow{2}{*}{$p$-value } \\
\hline & & $<77$ bpm n=219 & $\geq 77$ bpm n=130 & \\
\hline \multirow[t]{3}{*}{ ECG } & Heart rate (beats/min) & $65.58 \pm 6.88$ & $88.06 \pm 9.03$ & $<0.001$ \\
\hline & Left bundle branch block, $\mathrm{n}(\%)$ & $17(8 \%)$ & $15(12 \%)$ & 0.25 \\
\hline & Right bundle branch block, n (\%) & $22(10 \%)$ & $10(8 \%)$ & 0.57 \\
\hline \multirow[t]{9}{*}{ Echocardiography } & Aortic valve area $\left(\mathrm{cm}^{2}\right)$ & $0.65 \pm 0.23$ & $0.56 \pm 0.22$ & 0.002 \\
\hline & Aortic maximal velocity (cm.s-1) & $4.0 \pm 1.0$ & $4.1 \pm 0.8$ & 0.51 \\
\hline & Mean gradient $(\mathrm{mmHg})$ & $45.1 \pm 17.6$ & $44.3 \pm 17.6$ & 0.72 \\
\hline & LV ejection fraction (baseline, \%) & $55.4 \pm 14.0$ & $51.0 \pm 17.4$ & 0.016 \\
\hline & E/A ratio & $1.0 \pm 0.7$ & $1.5 \pm 1.2$ & 0.041 \\
\hline & E-wave deceleration time (ms) & $239.6 \pm 98.3$ & $182.2 \pm 90.3$ & 0.020 \\
\hline & Mitral regurgitation & & & 0.003 \\
\hline & Moderate & $23(13 \%)$ & $32(31 \%)$ & 0.001 \\
\hline & Severe & $3(2 \%)$ & $3(3 \%)$ & 0.67 \\
\hline \multirow{4}{*}{$\begin{array}{l}\text { Invasive } \\
\text { haemodynamics }\end{array}$} & Stroke volume index $\left(\mathrm{ml} / \mathrm{m}^{2}\right)$ & $30.71 \pm 8.21$ & $25.89 \pm 7.21$ & $<0.001$ \\
\hline & Cardiac index $\left(1 / \mathrm{min} / \mathrm{m}^{2}\right)$ & $2.21 \pm 0.49$ & $2.18 \pm 0.57$ & 0.67 \\
\hline & PA systolic pressure (mmHg) & $50.92 \pm 17.67$ & $50.71 \pm 17.80$ & 0.93 \\
\hline & Heart rate (beats/min) & $73.55 \pm 11.05$ & $86.11 \pm 13.82$ & $<0.001$ \\
\hline
\end{tabular}

groups. As expected, $\mathrm{HR}_{\text {ate }}$ measured during right heart catheterisation was significantly higher among HHR patients as compared with LHR patients, thereby corroborating the $\mathrm{HR}_{\text {ate }}$ measured on baseline ECG.

\section{PROCEDURAL CHARACTERISTICS}

Procedural characteristics are shown in Table 3. The majority of patients included in the present analysis underwent transfemoral TAVI (79\%). No significant differences in procedural characteristics were found between groups.

\section{CLINICAL OUTCOMES STRATIFIED ACCORDING TO BASELINE HR}

Clinical follow-up was complete for 338/349 (97\%) patients ( $\mathrm{n}=9$ lost to follow-up and $n=2$ refused follow-up). Event rates with adjusted hazard ratios (adj HR) and 30-day landmark analyses for all-cause mortality and cardiovascular death at two years stratified according to baseline $\mathrm{HR}_{\text {ate }}$ are provided in Table 4 .

Time-to-event curves for all-cause mortality and cardiovascular death at two-year follow-up are shown in Figure 2A and Figure 2B, respectively. A 30-day landmark analysis for all-cause mortality

Table 3. Procedural characteristics.

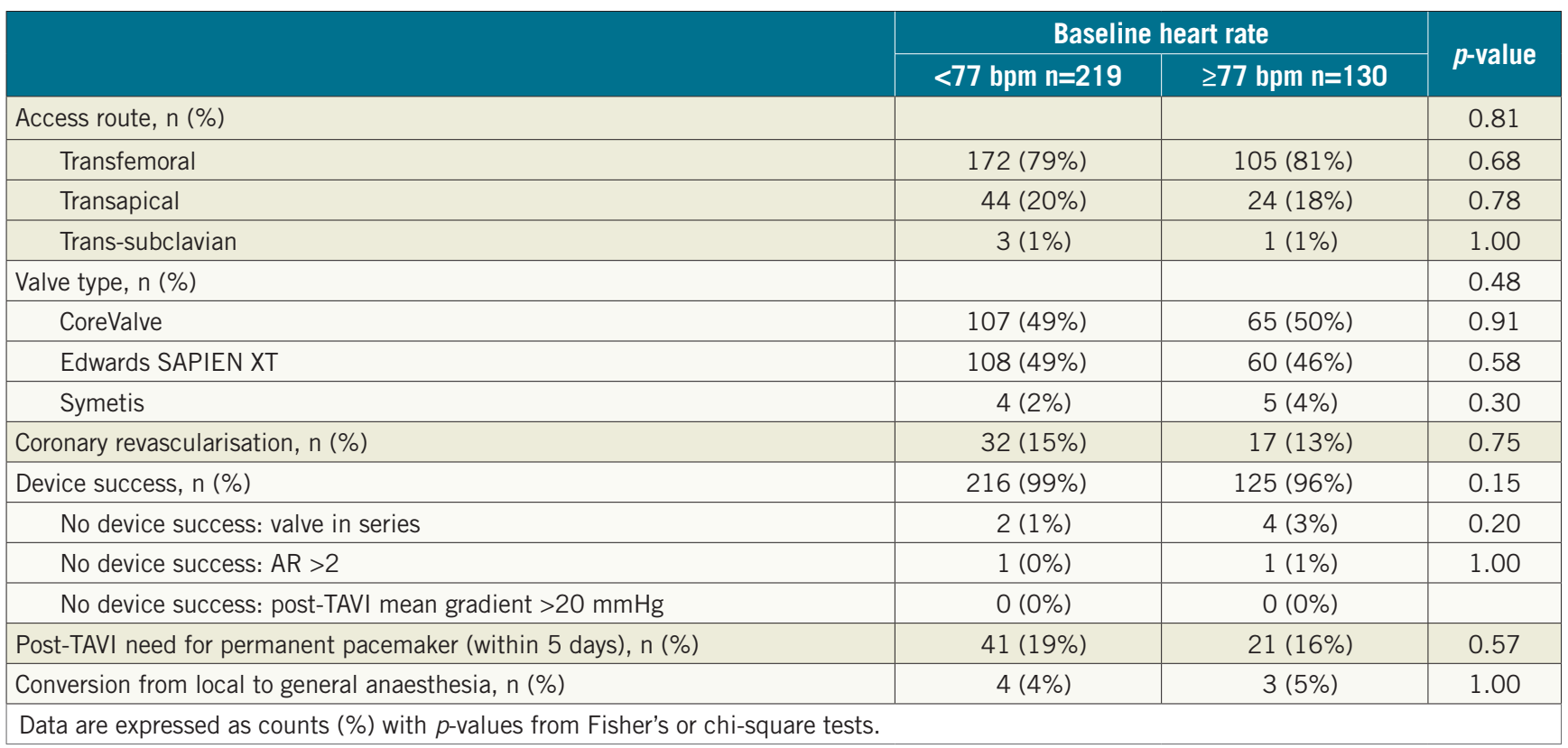


Table 4. Adjusted clinical outcomes at 2-year follow-up stratified by baseline resting heart rate.

\begin{tabular}{|c|c|c|c|c|c|}
\hline & & \multicolumn{2}{|c|}{ Baseline heart rate } & \multirow{2}{*}{$\begin{array}{l}<77 \text { vs. } \geq 77 \\
\text { HR (95\% CI) }\end{array}$} & \multirow{2}{*}{$p$-value } \\
\hline & & $<77$ bpm n=219 & $\geq 77$ bpm $n=130$ & & \\
\hline \multirow[t]{2}{*}{ 2-year follow-up } & All-cause death, n (\%) & $48(23.5)$ & $38(32.0)$ & $1.23(0.77-1.96)$ & 0.40 \\
\hline & Cardiovascular death, n (\%) & $31(15.6)$ & $24(20.8)$ & $1.15(0.64-2.07)$ & 0.64 \\
\hline \multirow{2}{*}{$\begin{array}{l}\text { Landmark } \\
30 \text { days to } 2 \text { years }\end{array}$} & All-cause death, $\mathrm{n}(\%)$ & $38(19.4)$ & $30(26.6)$ & $1.25(0.73-2.12)$ & 0.41 \\
\hline & Cardiovascular death, n (\%) & $24(12.5)$ & $16(15.0)$ & $1.03(0.51-2.08)$ & 0.95 \\
\hline \multicolumn{6}{|c|}{$\begin{array}{l}\text { Depicted are number of events (incidence rates from life tables, \%). Inverse probability of treatment weighted (IPTW) hazard ratios (HR [95\% } \\
\text { confidence intervals]) from Cox regressions. IPTW for high versus low heart rate calculated using the following baseline clinical variables: age, gender, } \\
\text { height, body mass index, diabetes mellitus, coronary artery disease, multivessel disease, previous myocardial infarction, cardiac surgery, percutaneous } \\
\text { coronary intervention, peripheral vascular disease, chronic obstructive pulmonary disease (COPD), renal failure, moderate or severe mitral regurgitation, } \\
\text { New York Heart Association (NYHA) functional Class III or IV (selected if } p<0.2 \text { on all-cause death at two years or } p<0.2 \text { on high versus low). Missing } \\
\text { data replaced with single imputation (COPD, NYHA II or IV, mitral regurgitation). }\end{array}$} \\
\hline
\end{tabular}

and cardiovascular death at two years is shown in Figure $\mathbf{2 C}$ and Figure 2D, respectively. As compared with baseline LHR, no significant differences in all-cause mortality or cardiovascular death were observed among patients with baseline HHR at two-year follow-up. On 30-day landmark analysis, no significant differences in all-cause mortality or cardiovascular death were observed among patients with baseline HHR on unadjusted or adjusted analysis at two-year follow-up (Table 4, Figure 2C, Figure 2D).

No significant interaction was observed between overall mortality (p-interaction 0.91 ) and cardiovascular death ( $\mathrm{p}$-interaction

A

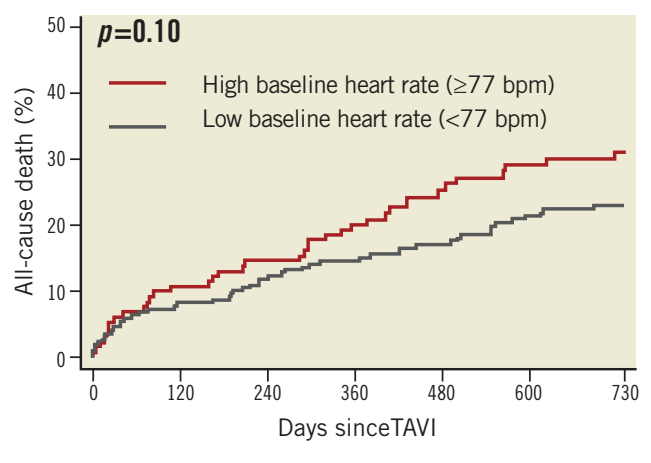

C

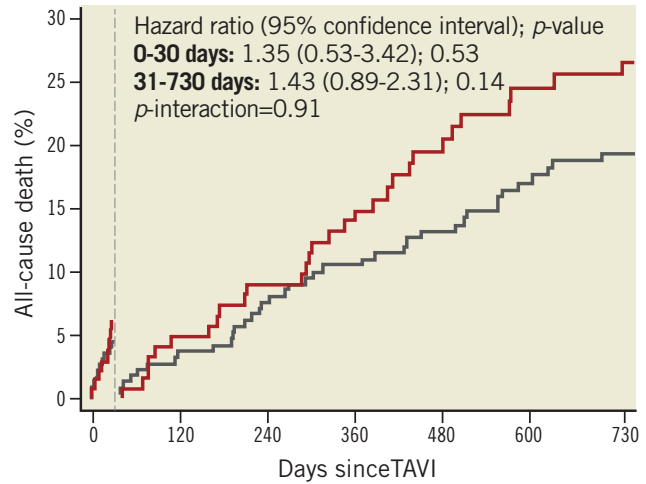

Number at risk

$\begin{array}{llllllll}\text { Low heart rate } & 219 & 200 & 191 & 186 & 156 & 146 & 128\end{array}$

$\begin{array}{lllllrrr}\text { High heart rate } & 130 & 115 & 110 & 101 & 82 & 73 & 63\end{array}$
0.44) event rates occurring before and after 30-day follow-up (Figure 2C, Figure 2D).

\section{CHANGES IN HR ate AFTER TAVI}

Changes in resting $\mathrm{HR}_{\text {ate }}$ measured on 12-lead ECGs before and after TAVI among patients remaining in normal sinus rhythm on discharge ECG $(n=197)$ are shown in Table 5 and Figure 3. Overall, the mean $\mathrm{HR}_{\text {ate }}$ increased after TAVI on discharge ECG. Among LHR patients, the mean $\mathrm{HR}_{\text {ate }}$ significantly increased following TAVI on discharge as compared with baseline ECG. Conversely,

B

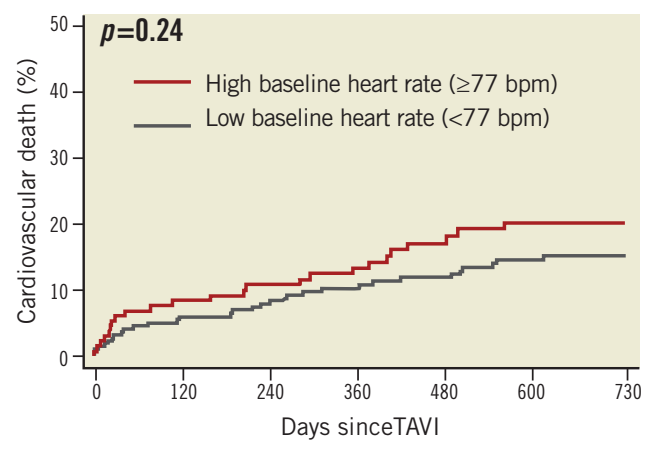

D

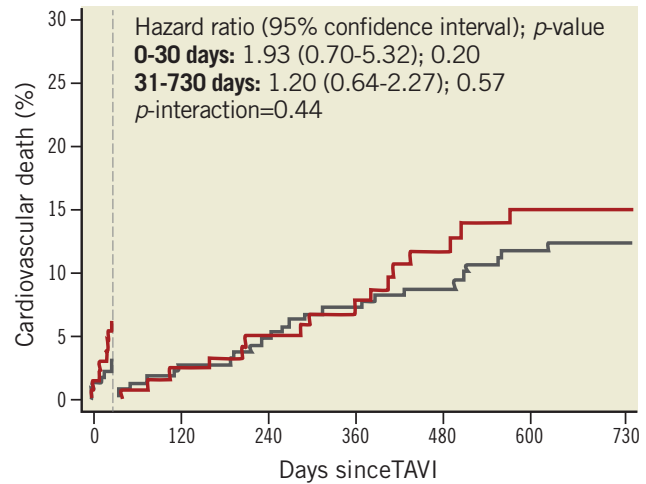

Number at risk

$\begin{array}{llllllll}\text { Low heart rate } & 219 & 200 & 191 & 186 & 156 & 146 & 128\end{array}$ $\begin{array}{lllllrrr}\text { High heart rate } & 130 & 115 & 110 & 101 & 82 & 73 & 63\end{array}$

Figure 2. Clinical outcomes according to baseline heart rate. Kaplan-Meier analysis of death (A) and cardiovascular death (B) at two years among patients undergoing transcatheter aortic valve implantation (TAVI) stratified according to low (heart rate $<77$ beats per minute [bpm]) versus high (heart rate $\geq 77 \mathrm{bpm}$ ) baseline resting heart rate. Thirty-day landmark analysis of death (C) and cardiovascular death (D) at two years among patients undergoing TAVI stratified according to low versus high resting heart rate at baseline. 
Table 5. Change in heart rate after transcatheter aortic valve implantation among patients remaining in sinus rhythm.

\begin{tabular}{|c|c|c|c|c|}
\hline & \multicolumn{2}{|c|}{ Heart rate } & \multirow{2}{*}{$\begin{array}{c}\text { Difference ( } 95 \% \text { CI } \\
\text { discharge - baseline) }\end{array}$} & \multirow{2}{*}{$p$-value } \\
\hline & Baseline & Discharge & & \\
\hline All patients $(\mathrm{N}=197)$ & $73.9 \pm 13.4$ & $77.3 \pm 11.5$ & 3.38 (1.54 to 5.22$)$ & $<0.001$ \\
\hline $\mathrm{HR}<77$ bpm $(\mathrm{N}=123)$ & $65.5 \pm 6.9$ & $73.8 \pm 10.6$ & 8.35 (6.26 to 10.44$)$ & $<0.001$ \\
\hline $\mathrm{HR} \geq 77 \mathrm{bpm}(\mathrm{N}=74)$ & $88.0 \pm 8.9$ & $83.1 \pm 10.6$ & $-4.88(-7.37$ to -2.39$)$ & $<0.001$ \\
\hline
\end{tabular}

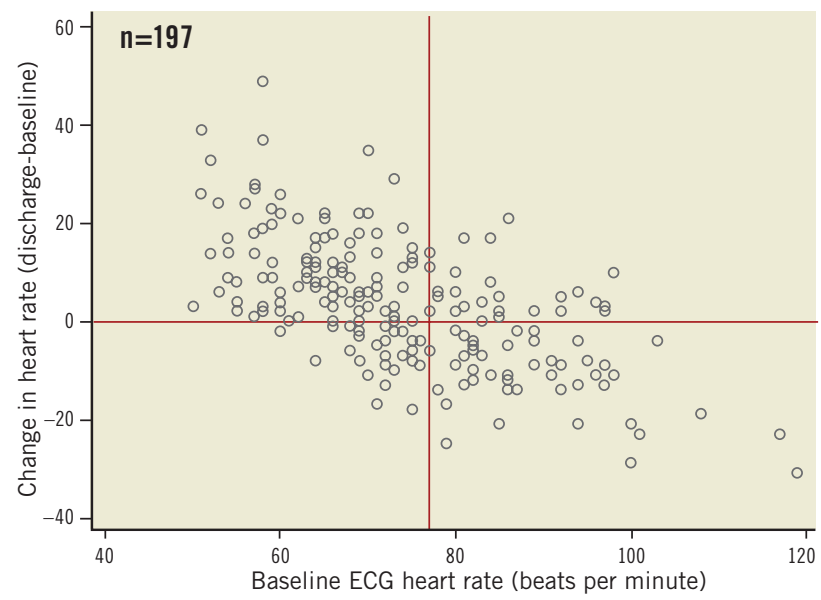

Figure 3. Scatter plot showing the changes in heart rate before and after transcatheter aortic valve implantation (TAVI) among patients remaining in normal sinus rhythm as measured on the baseline and discharge 12-lead electrocardiograms ( $n=197$ patients), respectively. The resting heart rate at baseline on the $x$-axis is plotted against the change in heart rate (delta heart rate) after TAVI, i.e., discharge heart rate minus baseline heart rate, on the y-axis.

among HHR patients, the mean $\mathrm{HR}_{\text {ate }}$ significantly decreased after TAVI on discharge as compared with baseline ECG.

\section{CLINICAL OUTCOMES STRATIFIED ACCORDING TO DISCHARGE HR}

Event rates with adj HRs for all-cause mortality and cardiovascular death and 30-day landmark analyses at two years stratified according to discharge $\mathrm{HR}_{\text {ate }}$ are provided in Table 6. Time-toevent curves for all-cause mortality and cardiovascular death at two-year follow-up stratified according to discharge $\mathrm{HR}_{\text {ate }}$ are shown in Figure 4A and Figure 4B, respectively. A landmark analysis at 30 days for all-cause mortality and cardiovascular death at two years is shown in Figure 4C and Figure 4D, respectively.

As compared with discharge LHR, no significant differences in all-cause mortality or cardiovascular mortality among discharge HHR patients were observed. On 30-day landmark analysis, discharge HHR was significantly associated with all-cause mortality at two-year follow-up (HR 2.30, 95\% CI: 1.16-4.56, p=0.017) although this significance was lost after extensive adjustment for comorbidities (adj HR 2.01, 95\% CI: 0.98-4.09, $\mathrm{p}=0.056$ ). A statistically significant interaction was observed for overall mortality (p-interaction 0.021) and cardiovascular death ( $\mathrm{p}$-interaction 0.031 ) events occurring before and after 30-day follow-up (Figure 4C, Figure 4D) for discharge $H_{\text {ate }}$.

\section{Discussion}

The main finding from the present study was that neither baseline nor discharge HHR was associated with overall or cardiovascular mortality two years after TAVI. Although patients with HHR had worse echocardiographic and invasive haemodynamic profiles at baseline as compared with LHR patients, this did not translate into worse clinical outcomes at two-year follow-up. A novel observation was that TAVI resulted in a significant physiological modification of the resting $\mathrm{HR}_{\text {ate }}$, i.e., the majority of LHR patients had a significant increase in resting $\mathrm{HR}_{\mathrm{ate}}$, whereas the majority of HHR patients exhibited a significant decrease in resting $\mathrm{HR}_{\text {ate }}$

Table 6. Adjusted clinical outcomes at 2-year follow-up stratified by discharge resting heart rate (normal sinus rhythm).

\begin{tabular}{|c|c|c|c|c|c|}
\hline & \multicolumn{2}{|c|}{ Discharge heart rate } & \multirow{2}{*}{$\begin{array}{c}<77 \text { vs } \geq 77 \\
\text { HR }(95 \% \text { CI) }\end{array}$} & \multirow{2}{*}{$p$-value } \\
\hline & & $<77$ bpm n=100 & $\geq 77$ bpm n=97 & & \\
\hline \multirow[t]{2}{*}{ 2-year follow-up } & All-cause death, $\mathrm{n}(\%)$ & $18(19.8)$ & $28(30.9)$ & $1.43(0.77-2.65)$ & 0.25 \\
\hline & Cardiovascular death, $\mathrm{n}(\%)$ & $13(14.2)$ & $17(19.6)$ & $1.14(0.54-2.39)$ & 0.74 \\
\hline \multirow{2}{*}{$\begin{array}{l}\text { Landmark } \\
30 \text { days to } 2 \text { years }\end{array}$} & All-cause death, $\mathrm{n}(\%)$ & $12(14.7)$ & $26(29.5)$ & $2.01(0.98-4.09)$ & 0.056 \\
\hline & Cardiovascular death, n (\%) & $7(8.7)$ & $15(17.9)$ & $1.80(0.71-4.58)$ & 0.21 \\
\hline
\end{tabular}

Depicted are number of events (incidence rates from life tables, \%). Inverse probability of treatment weighted (IPTW) hazard ratios (HR [95\% confidence intervals]) from Cox regressions. IPTW for high versus low heart rate calculated using the following baseline clinical variables: age, gender, height, body mass index, diabetes mellitus, coronary artery disease, multivessel disease, previous myocardial infarction, cardiac surgery, percutaneous coronary intervention, peripheral vascular disease, chronic obstructive pulmonary disease (COPD), renal failure, moderate or severe mitral regurgitation, New York Heart Association (NYHA) functional Class III or IV (selected if $p<0.2$ on all-cause death at two years or $p<0.2$ on high versus low). Missing data replaced with single imputation (COPD, NYHA II or IV, mitral regurgitation). 
A

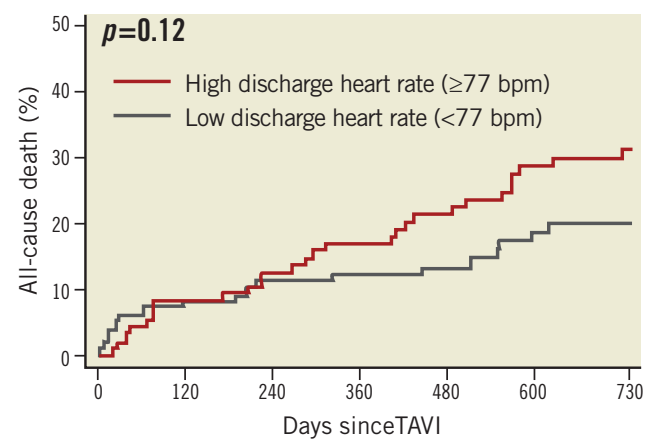

C

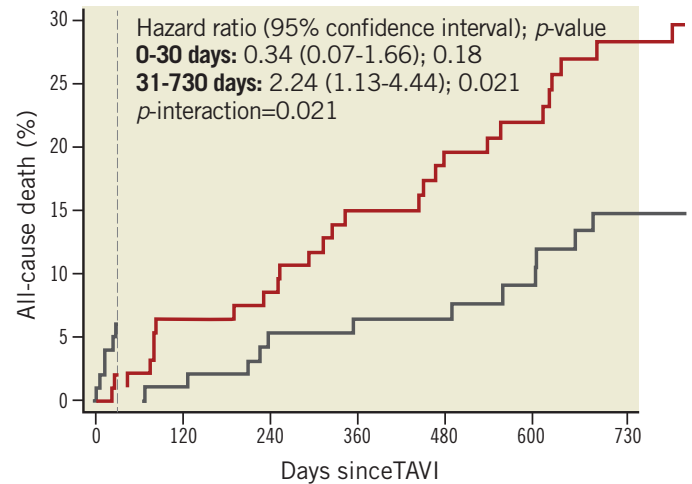

Number at risk

$\begin{array}{llllllll}\text { Low heart rate } & 100 & 91 & 88 & 87 & 67 & 62 & 54\end{array}$

$\begin{array}{llllllll}\text { High heart rate } & 97 & 88 & 84 & 80 & 67 & 58 & 51\end{array}$
B

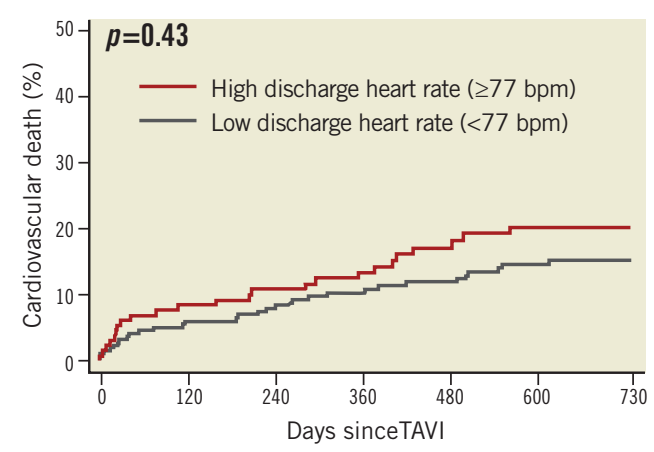

D

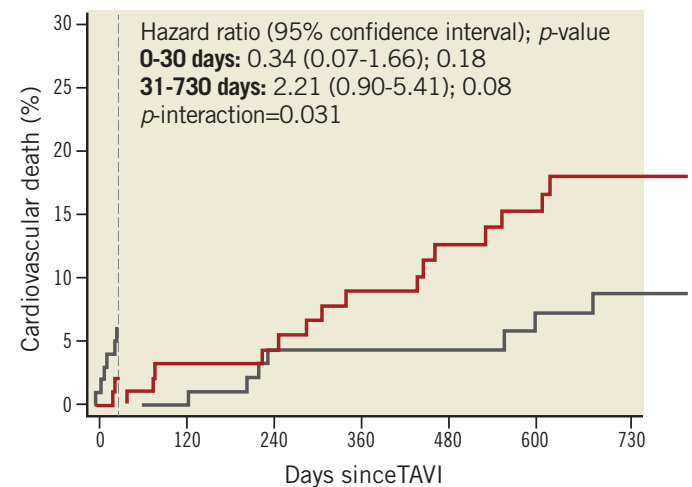

Number at risk

$\begin{array}{llllllll}\text { Low heart rate } & 100 & 91 & 88 & 87 & 67 & 62 & 54\end{array}$

$\begin{array}{lrllllll}\text { High heart rate } & 97 & 88 & 84 & 80 & 67 & 58 & 51\end{array}$

Figure 4. Clinical outcomes according to discharge heart rate. Kaplan-Meier analysis of death (A) and cardiovascular death (B) at two years among patients undergoing transcatheter aortic valve implantation (TAVI) stratified according to low (heart rate $<77$ beats per minute [bpm]) versus high (heart rate $\geq 77 \mathrm{bpm}$ ) discharge resting heart rate. Thirty-day landmark analysis of death (C) and cardiovascular death (D) at two years among patients undergoing TAVI stratified according to low versus high resting heart rate at discharge.

after TAVI (Figure 3). The latter observation may explain the lack of effect of baseline resting $\mathrm{HR}_{\text {ate }}$ on clinical outcomes after TAVI. In contrast to baseline $\mathrm{HR}_{\text {ate }}$, a discharge HHR was significantly associated with overall mortality two years after TAVI on 30-day landmark analysis, although this significance was lost after extensive adjustment (HR 2.01, 95\% CI: 0.98-4.09, $\mathrm{p}=0.056$ ).

\section{RELATIONSHIP BETWEEN RESTING HR ate $_{\text {AND OUTCOMES }}$ IN CARDIOVASCULAR DISEASE}

A significant association between resting $\mathrm{HR}_{\text {ate }}$ and mortality has been reported among patients with a variety of cardiovascular diseases, including acute coronary syndromes ${ }^{18}$, and hypertension ${ }^{19}$. Furthermore, $\mathrm{HR}_{\text {ate }}$ was found to be directly related to the risk of death, cardiovascular death, or admission to hospital in patients with heart failure ${ }^{20}$, and $\mathrm{HR}_{\text {ate }}$ reduction was found to be associated with improved outcomes ${ }^{21}$. Resting $\mathrm{HR}_{\text {ate }}$ is included in several risk assessment algorithms for patients after acute coronary syndromes, such as the Global Registry of Acute Coronary Events risk prediction (GRACE) score and the Thrombolysis In Myocardial Infarction (TIMI) risk score ${ }^{22,23}$. Ivabradine is a selective inhibitor of the funny current $\left(\mathrm{I}_{f}\right)$, which results in $\mathrm{HR}_{\text {ate }}$ reduction with no other apparent direct cardiovascular effects ${ }^{24}$. In the Ivabradine for patients with stable coronary artery disease and left-ventricular systolic dysfunction (BEAUTIFUL) trial, ivabradine-induced $\mathrm{HR}_{\text {ate }}$ reduction did not affect the primary composite endpoint of cardiovascular death, hospital admission for acute myocardial infarction, and hospital admission for new-onset or worsening heart failure ${ }^{24}$. However, it did reduce the secondary endpoints of hospital admission for fatal and non-fatal myocardial infarction and coronary revascularisation. Furthermore, a subanalysis of the BEAUTIFUL trial revealed that an $\mathrm{HR}_{\text {ate }}$ of $\geq 70 \mathrm{bpm}$ was associated with a $34 \%$ increased risk of cardiovascular death, a $53 \%$ increase in admission to hospital for heart failure, and a $46 \%$ increase for admission to hospital for myocardial infarction compared with $\mathrm{HR}_{\text {ate }}$ lower than $70 \mathrm{bpm}$, even after adjustment for other predictors of outcomes ${ }^{7}$. In the Systolic Heart failure treatment with the $\mathrm{I}_{f}$ inhibitor ivabradine Trial (SHIFT), comprising patients in sinus rhythm with a resting $\mathrm{HR}_{\text {ate }} \geq 70 \mathrm{bpm}$ (in contrast to the $60 \mathrm{bpm}$ cut-off used in the BEAUTIFUL trial) and LVEF $\leq 35 \%$, ivabradine was associated with an $18 \%$ relative risk reduction in the composite primary endpoint of cardiovascular death or hospital admission for worsening heart failure $(\mathrm{p}<0.0001)^{14}$. 


\section{RELATIONSHIP BETWEEN RESTING HR ate $_{\text {AND OUTCOMES }}$ IN PATIENTS WITH AS}

Among patients with asymptomatic AS, recent studies have also shown resting $\mathrm{HR}_{\text {ate }}$ to be an independent predictor of cardiovascular mortality ${ }^{8}$. In a subanalysis of the Simvastatin Ezetimibe in Aortic Stenosis (SEAS) study, Greve et al assessed the prognostic value of an elevated resting $\mathrm{HR}_{\text {ate }}$ during watchful waiting in asymptomatic $\mathrm{AS}^{8}$. An elevated resting $\mathrm{HR}_{\text {ate }}$ was observed to be independently associated with major cardiovascular events and cardiovascular death during long-term follow-up even after adjusting for other predictors of outcomes ${ }^{8}$. Dumonteil et al recently demonstrated that TAVI normalises SNS overactivity ${ }^{9}$. The investigators directly measured muscle sympathetic nerve activity and arterial baroreflex gain in 14 patients with severe symptomatic AS before and a week after TAVI and in 14 control patients without $\mathrm{AS}^{9}$. They found that patients with AS had increased SNS activity associated with a decrease in sympathetic arterial baroreflex gain compared with controls, and that TAVI normalised these parameters 9 . In the present study, the normalisation of sympathetic overactivity may explain the significant $\mathrm{HR}_{\text {ate }}$ reduction observed among HHR patients after TAVI. This may ultimately explain the lack of differences in clinical outcomes observed between patients with HHR and LHR after TAVI. We observed that HHR patients had significantly lower stroke volumes and stroke volume indices on right heart catheterisation as compared with LHR patients. It is likely that this low flow state leads to activation of the SNS leading to an increase in $\mathrm{HR}_{\text {ate }}$ in an effort to compensate for the low stroke volume. We also observed that patients with LHR had a significant increase in $\mathrm{HR}_{\text {ate }}$ after TAVI. The reason for this is unclear. Further studies correlating changes in heart rate after TAVI with post-procedural changes in cardiac output and stroke volume are required in order to explain this phenomenon.

\section{Limitations}

There are a number of limitations that need to be considered when interpreting this study. First, the present study was a single-centre retrospective study. Even though all data were prospectively collected and all events adjudicated by an independent clinical events committee, our results may contain unmeasured bias. Second, the sample size is relatively small $(\mathrm{n}=349)$, and only 197 patients had available data for discharge analysis. However, to the best of our knowledge, this is the first study to question the association between resting sinus rhythm $\mathrm{HR}_{\text {ate }}$ and clinical outcomes in TAVI patients. Third, this is not a consecutive patient series, as patients with missing ECGs or those who received ECGs $>30$ days prior to TAVI were excluded. Furthermore, not all included patients had discharge ECGs available. Finally, there are other factors that can influence resting $\mathrm{HR}_{\text {ate }}$ apart from SNS activity.

\section{Conclusions}

Neither baseline nor discharge resting HHR was associated with all-cause mortality or cardiovascular death after TAVI.

\section{Impact on daily practice}

Resting sinus rhythm heart rate is known to be a modifiable risk factor for cardiovascular disease, including aortic stenosis. However, there have been no studies to date assessing the effect of baseline and discharge resting sinus rhythm heart rate on clinical outcomes after transcatheter aortic valve implantation (TAVI). We observed that resting sinus rhythm heart rate at baseline and discharge had no effect on two-year mortality rates after TAVI.

\section{Conflict of interest statement}

S. Windecker has received research contracts to the institution from Abbott, Boston Scientific, Biotronik, Medtronic, Edwards Lifesciences and St. Jude. The other authors have no conflicts of interest to declare.

\section{References}

1. Fox K, Borer JS, Camm AJ, Danchin N, Ferrari R, Lopez Sendon JL, Steg PG, Tardif JC, Tavazzi L, Tendera M; Heart Rate Working Group. Resting heart rate in cardiovascular disease. J Am Coll Cardiol. 2007;50:823-30.

2. Palatini P, Julius S. Elevated heart rate: a major risk factor for cardiovascular disease. Clin Exp Hypertens. 2004;26:637-44.

3. Palatini P, Benetos A, Julius S. Impact of increased heart rate on clinical outcomes in hypertension: implications for antihypertensive drug therapy. Drugs. 2006;66:133-44.

4. Diaz A, Bourassa MG, Guertin MC, Tardif JC. Long-term prognostic value of resting heart rate in patients with suspected or proven coronary artery disease. Eur Heart J. 2005;26:967-74.

5. Gillmann MW, Kannel WB, Belanger A, D’Agostino RB. Influence of heart rate on mortality among patients with hypertension: the Framingham Study. Am Heart J. 1993;125:1148-54.

6. Palatini P, Casiglia E, Julius S, Pessina AC. High heart rate: a risk factor for cardiovascular death in elderly men. Arch Intern Med. 1999;159:585-92.

7. Fox K, Ford I, Steg PG, Tendera M, Robertson M, Ferrari R; BEAUTIFUL investigators. Heart rate as a prognostic risk factor in patients with coronary artery disease and left-ventricular systolic dysfunction (BEAUTIFUL): a subgroup analysis of a randomized controlled trial. Lancet. 2008;372:817-21.

8. Greve AM, Bang CN, Berg RM, Egstrup K, Rossebo AB, Boman K, Nienaber CA, Ray S, Gohlke-Baerwolf C, Nielsen OW, Okin PM, Devereux RB, Kober L, Wachtell K. Resting heart rate and risk of adverse cardiovascular outcomes in asymptomatic aortic stenosis: the SEAS study. Int J Cardiol. 2015;180:122-8.

9. Dumonteil N, Vaccaro A, Despas F, Labrunee M, Marcheix B, Lambert E, Esler M, Carrie D, Senard JM, Galinier M, Pathak A. Transcatheter aortic valve implantation reduces sympathetic activity and normalizes arterial spontaneous baroreflex in patients with aortic stenosis. JACC Cardiovasc Interv. 2013;6:1195-202.

10. Stortecky S, Buellesfeld L, Wenaweser P, Heg D, Pilgrim T, Khattab AA, Gloekler S, Huber C, Nietlispach F, Meier B, Jüni P, 
Windecker S. Atrial fibrillation and aortic stenosis: impact on clinical outcomes among patients undergoing transcatheter aortic valve implantation. Circ Cardiovasc Interv. 2013;6:77-84.

11. Amat-Santos IJ, Rodés-Cabau J, Urena M, DeLarochellière R, Doyle D, Bagur R, Villeneuve J, Côté M, Nombela-Franco L, Philippon F, Pibarot P, Dumont E. Incidence, predictive factors, and prognostic value of new-onset atrial fibrillation following transcatheter aortic valve implantation. J Am Coll Cardiol. 2012;59:178-88.

12. Houthuizen P, Van Garsse LA, Poels TT, de Jaegere P, van der Boon RM, Swinkels BM, ten Berg JM, van der Kley F, Schalij MJ, Bann J Jr, Cocchieri R, Brueren GR, van Straten AH, den Heijer P, Bentala M, van Ommen V, Kluin J, Stella PR, Prins MH, Maessen JG, Prinzen FW. Left bundle-branch block induced by transcatheter aortic valve implantation increases risk of death. Circulation. 2012;126:720-8.

13. Testa L, Latib A, De Marco F, de Carlo M, Agnifili M, Latini RA, Petronio AS, Ettori F, Poli A, De Servi S, Ramondo A, Napodano M, Klugmann S, Ussia GP, Tamburino C, Brambilla N, Colombo A, Bedogni F. Clinical impact of persistent left bundlebranch block after transcatheter aortic valve implantation with CoreValve Revalving System. Circulation. 2013;127:1300-7.

14. Swedberg K, Komajda M, Böhm M, Borer JS, Ford I, DubostBrama A, Lerebours G, Tavazzi L; SHIFT Investigators. Ivabradine and outcomes in chronic heart failure (SHIFT): a randomized placebo-controlled study. Lancet. 2010;376:875-85.

15. O’Sullivan CJ, Stortecky S, Bütikofer A, Heg D, Zanchin T, Huber C, Pilgrim T, Praz F, Buellesfeld L, Khattab AA, Blöchlinger S, Carrel T, Meier B, Zbinden S, Wenaweser P, Windecker S. Impact of mitral regurgitation on clinical outcomes of patients with low-ejection fraction, low-gradient severe aortic stenosis undergoing transcatheter aortic valve implantation. Circ Cardiovasc Interv. 2015;8:e001895.

16. O'Sullivan CJ, Stortecky S, Heg D, Pilgrim T, Hosek N, Buellesfeld L, Khattab AA, Nietlispach F, Moschovitis A, Zanchin T, Meier B, Windecker S, Wenaweser P. Clinical outcomes of patients with low-flow, low-gradient, severe aortic stenosis and either preserved or reduced ejection fraction undergoing transcatheter aortic valve implantation. Eur Heart J. 2013;34:3437-50.

17. Kappetein AP, Head SJ, Généreux P, Piazza N, van Mieghem NM, Blackstone EH, Brott TG, Cohen DJ, Cutlip DE, van Es, GA, Hahn RT, Kirtane AJ, Krucoff MW, Kodali S,
Mack MJ, Mehran R, Rodès-Cabau J, Vranckx P, Webb JG, Windecker S, Serruys PW, Leon MB. Updated standardized endpoint definitions for transcatheter aortic valve implantation: the Valve Academic Research Consortium-2 consensus document. J Am Coll Cardiol. 2012;60:1438-54.

18. Kovar D, Cannon CP, Bentley JH, Charlesworth A, Rogers WJ. Does initial and delayed heart rate predict mortality in patients with acute coronary syndromes? Clin Cardiol. 2004;27:80-6.

19. Palatini P, Thijs L, Staessen JA, Fagard RH, Bulpitt CJ, Clement DL, de Leeuw PW, Jaaskivi M, Leonetti G, Nachev C, O'Brien ET, Parati G, Rodicio JL, Roman E, Sarti C, Tuomilehto J; Systolic Hypertension in Europe (Syst-Eur) Trial Investigators. Predictive value of clinic and ambulatory heart rate for mortality in elderly subjects with systolic hypertension. Arch Intern Med. 2002;162:2313-21.

20. Pocock SJ, Wang D, Pfeffer MA, Yusuf S, McMurray JJ, Swedberg KB, Ostergren J, Michelson EL, Pieper KS, Granger CB. Predictors of mortality and morbidity in patients with chronic heart failure. Eur Heart J. 2006;27:65-75.

21. Flannery G, Gehrig-Mills R, Billah B, Krum H. Analysis of randomized controlled trials on the effect of magnitude of heart rate reduction on clinical outcomes in patients with systolic chronic heart failure receiving beta-blockers. Am J Cardiol. 2008;101: 865-9.

22. Eagle KA, Lim MJ, Dabbous OH, Pieper KS, Goldberg RJ, Van de Werf F, Goodman SG, Granger CB, Steg PG, Gore JM, Budaj A, Avezum A, Flather MD, Fox KA; GRACE Investigators. A validated prediction model for all forms of acute coronary syndrome: estimating the risk of 6-month postdischarge death in an international registry. JAMA. 2004;291:2727-33.

23. Morrow DA, Antman EM, Charlesworth A, Cairns R, Murphy SA, de Lemos JA, Giugliano RP, McCabe CH, Braunwald E. TIMI risk score for ST-elevation myocardial infarction: a convenient, bedside, clinical score for risk assessment at presentation. An Intravenous nPA for Treatment of Infarcting Myocardium Early II Trial substudy. Circulation. 2000;102:2031-7.

24. Fox K, Ford I, Steg PG, Tendera M, Ferrari R; BEAUTIFUL Investigators. Ivabradine for patients with stable coronary artery disease and left-ventricular systolic dysfunction (BEAUTIFUL): a randomized, double-blind, placebo-controlled trial. Lancet. 2008;372:807-16. 